\title{
Programming of the reproductive axis by hormonal and genetic manipulation in mice
}

\author{
Susana Beatriz Rulli ${ }^{1}$, María Julia Cambiasso ${ }^{2}$ and Laura Daniela Ratner $^{1}$ \\ ${ }^{1}$ Instituto de Biología y Medicina Experimental- Consejo Nacional de Investigaciones Científicas y Técnicas, Buenos \\ Aires, Argentina and ${ }^{2}$ Instituto de Investigación Médica Mercedes y Martín Ferreyra, INIMEC-CONICET- Universidad \\ Nacional de Córdoba, Córdoba, Argentina
}

Correspondence should be addressed to S B Rulli; Email: srulli@ibyme.conicet.gov.ar

\begin{abstract}
In mammals, the reproductive function is controlled by the hypothalamic-pituitary-gonadal axis. During development, mechanisms mediated by gonadal steroids exert an imprinting at the hypothalamic-pituitary level, by establishing sexual differences in the circuits that control male and female reproduction. In rodents, the testicular production of androgens increases drastically during the fetal/ neonatal stage. This process is essential for the masculinization of the reproductive tract, genitals and brain. The conversion of androgens to estrogens in the brain is crucial for the male sexual differentiation and behavior. Conversely, feminization of the brain occurs in the absence of high levels of gonadal steroids during the perinatal period in females. Potential genetic contribution to the differentiation of brain cells through direct effects of genes located on sex chromosomes is also relevant. In this review, we will focus on the phenotypic alterations that occur on the hypothalamic-pituitary-gonadal axis of transgenic mice with persistently elevated expression of the human chorionic gonadotropin hormone (hCG). Excess of endogenously synthesized gonadal steroids due to a constant hCG stimulation is able to disrupt the developmental programming of the hypothalamic-pituitary axis in both transgenic males and females. Locally produced estrogens by the hypothalamic aromatase might play a key role in the phenotype of these mice. The 'four core genotypes' mouse model demonstrated a potential influence of sex chromosome genes in brain masculinization before critical periods of sex differentiation. Thus, hormonal and genetic factors interact to regulate the local production of the neurosteroids necessary for the programming of the male and female reproductive function.

Reproduction (2018) 156 R101-R109
\end{abstract}

\section{Introduction}

The hypothalamic-pituitary-gonadal (HPG) axis is essential for the normal function of the reproductive system in both males and females. Any alteration in the regulation of the different hormones or receptors involved in this process is enough to cause infertility. If these alterations occur during a critical period of fetal or postnatal development, the effects can be permanent and trigger, in addition to infertility, pathologies such as cancer, metabolic disorders and cardiovascular dysfunctions that are manifested in adulthood (Gluckman et al. 2008, Homburg 2009, Gore et al. 2015). It is remarkable that while the critical period of sexual differentiation includes fetal and early postnatal stages, the manifestation of certain pathologies and dysfunctions occurs later in life, beginning at puberty. This hypothesis, based on the developmental origin of adult diseases has become increasingly relevant in the field of reproductive endocrinology. The most significant cases in humans are infertility, polycystic ovary syndrome (PCOS), metabolic syndrome, cardiovascular diseases and diabetes (Gluckman et al. 2008, Homburg 2009).
In recent years, there has been growing interest in identifying potential adverse human health effects arising from environmental endocrine disruptors (Gore et al. 2015). The major disrupting agents described are those that mimic or antagonize the action of steroid hormones. However, endogenous hormones can also be considered endocrine disruptors when these are produced beyond the normal range of concentration or outside the critical time-window and may affect the normal development of the fetus/neonate. Pathologies such as congenital adrenal hyperplasia or PCOS that cause hyperandrogenism in the maternal environment are clear examples of inappropriate exposure to endogenous hormones during human development (Homburg 2009). Women exposed to excess androgens during early gestation exhibit hyperandrogenism, oligomenorrhea, polycystic ovary, in addition to $\mathrm{LH}$ hypersecretion, deficient embryonic development, insulin resistance with abdominal obesity, and hyperlipidemia (Homburg 2009). Epidemiological and experimental studies have revealed that in utero exposure to steroid hormones or endocrine disruptors may also influence the risk of tumor development 
in adult life (Halakivi-Clarke et al. 2000, Palmer et al. 2006). However, the relationship between the intrauterine exposure and tumorigenesis is still poorly understood, and the identification of these mechanisms is of particular interest. Experimental animal models with excess of natural or synthetic steroid hormones have been instrumental in deciphering their impact on the reproductive physiology, both in males and females (Hakim et al. 2017, Paixao et al. 2017). The induction of prenatal hyperandrogenism in female Rhesus monkeys by testosterone administration has been pivotal for understanding the basis of PCOS (Abbott et al. 2009). Studies on sheep and rodents have also provided important information on this subject (Padmanabhan \& Veiga-Lopez 2013, Paixao et al. 2017).

The precise mechanisms by which steroid hormones program the reproductive neuroendocrine axis and cause reproductive dysfunctions are not completely understood and are still under investigation. In contrast to the experimental models with exogenously administered androgens, which can exceed the physiological levels, the challenge is to identify the pattern of response to endogenously produced steroids under different experimental conditions. In addition to the gonadal hormones, recent evidence indicates that numerous sex-specific, genetic and epigenetic factors modulate sex differences in the brain and other tissues during development and may impact on the reproductive and metabolic processes in adulthood (Arnold et al. 2013, Arnold 2017).

In this review, we will summarize the neuroendocrine changes affecting the reproductive axis in genetically manipulated male and female mice. A transgenic mouse model with endogenously elevated sex steroids induced by human chorionic gonadotropin (hCG) became a useful tool to study the influence of gonadal steroids on the developmental programming of the hypothalamicpituitary-gonadal function in males and females (Rulli et al. 2002, 2003, Gonzalez et al. 2011, 2014). On the other hand, studies with the 'four core genotypes' (FCG) mouse model demonstrated a potential influence of sex chromosome genes in brain masculinization before critical periods of sex differentiation and contribute to discriminate between the effects of sex chromosome complement and the gonadal phenotype (Arnold \& Chen 2009, Cisternas et al. 2015, Itoh et al. 2015, Cisternas et al. 2017).

\section{The influence of steroids on the neuroendocrine regulation during development}

The onset of the reproductive function in mammals comprises a series of events that include the activation of the gonadotropic axis, the sexual differentiation of the brain and the development of the reproductive tract. Proper functioning in adulthood depends on adequate development of the axis during a critical time-window, which, in rodents ranges from fetal to early postnatal stage (Weisz \& Ward 1980, Rhoda et al. 1984, Huhtaniemi 1994, O'Shaughnessy et al. 1997, O'Shaughnessy et al. 1998, Arnold 2017). This phenomenon is sexually dimorphic and depends on gonadal steroids (Negri-Cesi et al. 2008, Gore et al. 2015): prenatal androgens masculinize the reproductive tract and perinatal estradiol (derived from testosterone) masculinizes the brain. Previous to this critical time window in which hormones have a key role, a genetic sex-chromosome component appears to be involved in the brain sexual differentiation (Cisternas et al. 2015, Arnold 2017).

The normal fetal testis is steroidogenically active and produces substantial levels of androgens that, in rodents, peak at the end of gestation (days 17-18 in mice; 18.519.5 in rats) (Weisz \& Ward 1980, Huhtaniemi 1994, O'Shaughnessy et al. 1998). This process is necessary for the masculinization of the reproductive tract, and can be exerted directly through the androgen receptor, either by testosterone or by its metabolite $5 \alpha$-dihydrotestosterone (DHT), synthesized by the enzyme $5 \alpha$-reductase (Wilson \& Davies 2007). A second surge of testosterone occurs soon after birth (Rhoda et al. 1984). Neonatally produced testosterone is aromatized to estradiol by the enzyme P450 aromatase in the brain, thus allowing estradiol to exert its effect through estrogen receptors (McCarthy 2008, Ruiz-Palmero et al. 2013).The conversion of gonadal testosterone to locally produced estradiol is crucial for the male sexual differentiation of the brain and affects sexual behavior (Negri-Cesi et al. 2008, Konkle \& McCarthy 2011). Castration of males during the critical period of neonatal differentiation causes brain feminization (acquisition of typically female responses) or brain demasculinization (loss of typically male responses) (McCarthy 2008, Negri-Cesi et al. 2008).

In female development, the absence of testicular hormones is considered sufficient to achieve the differentiation of a brain with female characteristics. Although it has been proposed that the fetal ovary is relatively quiescent compared to the testis, androgens and estrogens have been shown to be detectable in the late fetal stage (Wilson \& Davies 2007). Interestingly, the brain feminization is maintained by the active suppression of masculinization via DNA methylation (Nugent et al. 2015). In females, abnormal exposure to testosterone during critical periods of differentiation may cause masculinization (acquisition of typically male responses) or defeminization (loss of typically female responses), ovulatory and virilizing genital alterations. Depending on the time window of exposure, behavioral and ovulatory dysfunctions can coexist without virilized genitalia, such as during late prenatal stage (Gorski 1985, Rhees et al. 1997, Robinson 2006).

During gestation, the fetus is exposed to its own hormones, placental steroids and hormones of maternal 
origin that are capable of crossing the placental barrier. However, the $\alpha$-fetoprotein produced by the fetus and the yolk sac has affinity for estradiol and sequesters it, thus protecting the female brain from the effects of maternal or placental estrogens (Bakker et al. 2006). During a period between birth and puberty, estrogens play a role in feminization of neural and behavioral traits of female rodents (Bakker \& Baum 2008).

\section{The 'FCG' model: a transgenic mouse model for studying the sex chromosome influence}

A genetic contribution of sex chromosomes to the differentiation of brain cells has been demonstrated with the FCG mouse model (Carruth et al. 2002, Scerbo et al. 2014, Arnold 2017). In this model, the testisdetermining Sry gene is deleted from the $\mathrm{Y}$ chromosome and inserted onto an autosomal chromosome. The $Y$ and autosomal chromosomes segregate independently and give rise to four different genotypes (Fig. 1). As a result, mice bearing the Sry gene develop testes and are masculinized, whereas mice lacking the Sry gene develop a female phenotype, irrespective of their sex chromosome (DeVries et al. 2002, Arnold \& Chen 2009). This model allows comparing the effects of gonadal sex and chromosome sex complement.

The first neural phenotype reported to be influenced by sex chromosome was the expression of the rate-limiting enzyme in catecholamine biosynthesis, the tyrosine hydroxylase, in mesencephalic neurons harvested from embryonic day 14 (before the critical period of brain masculinization). Using the FCG mouse model, Carruth et al. (2002) demonstrated that XY cultures have more tyrosine hydroxylase-immunoreactive neurons than $X X$ cultures irrespective of the gonadal type of the embryos. At the same time, the FCG model was used to study sexually dimorphic brain and behavioral phenotypes in adulthood. Most of the sexually dimorphic phenotypes

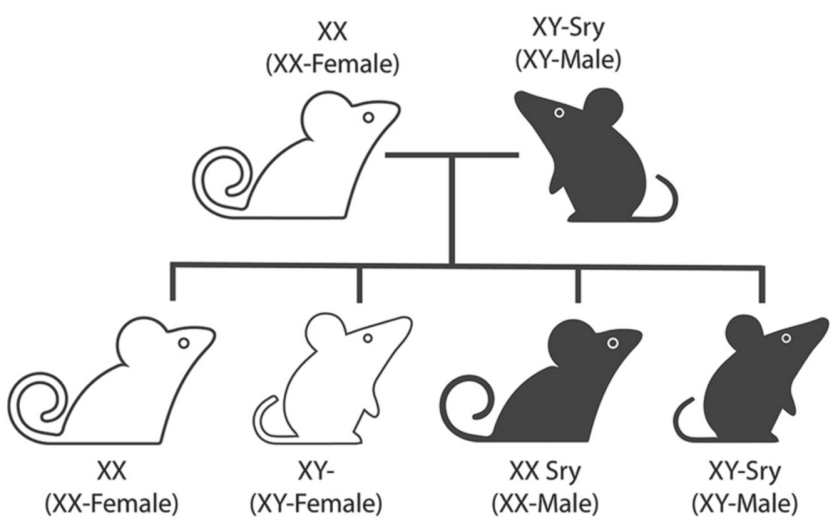

Figure 1 Four core genotypes (FCG) mice obtained by crossbreeding XX females with XY-Sry transgenic males. Representative figure showing the genotypes of $X X$ and $X Y$ mice with testes ( $X X$ Sry, $X Y^{-}$Sry) and $X X$ and $X Y$ mice with ovaries $\left(X X, X Y^{-}\right)$. (male copulatory behavior, social exploration behavior and sexually dimorphic neuroanatomical structures in the hypothalamus and lumbar spinal cord) correlated with the presence of ovaries or testes, and therefore, reflect the hormonal output of the gonads. However, the density of vasopressin-immunoreactive fibers in the lateral septum of both male and female mice with $X Y$ sex chromosomes were more masculine than XX mice (De Vries et al. 2002), indicating that sex chromosome genes contribute directly to the development of a sex difference in the brain. Moreover, another sex chromosome effects have also been detected on aggression, body weight, habit formation and response to brain injury (Arnold \& Chen 2009, Forger et al. 2015). Importantly, many reports indicate that sex chromosomes impact the incidence and progression of diverse models of brain diseases such as multiple sclerosis (Palaszynski et al. 2005, SmithBouvier et al. 2008), systemic lupus erythematosus (Smith-Bouvier et al. 2008), major depressive disorders (Seney et al. 2013a,b) and neural tube closure defects (Chen et al. 2008).

Recently, we have demonstrated sex chromosomeinduced differences in P450 aromatase expression in the developing mouse brain as early as gestational day 16 (GD16) (Cisternas et al. 2015). Using the FCG mouse model, we found that XY mouse embryos show higher P450 aromatase expression than the brain of XX embryos, independently of gonadal sex. Furthermore, estradiol or DHT increases P450 aromatase expression in cultures of anterior amygdala neurons derived from $X X$ embryos, but not in those derived from XY embryos. The mechanism of P450 aromatase regulation by hormones involves ER $\beta$ since the antiandrogen flutamide is not able to prevent $\mathrm{P} 450$ aromatase increase by $\mathrm{DHT}$, while the ER $\beta$ antagonist PHTPP blocked the effect of both estradiol and DHT (Cisternas et al. 2017). In addition, $3 \beta$-diol, which has been reported to preferentially bind ER $\beta$ (Kuiper et al. 1998), mimics the effects of estradiol and DHT on P450 aromatase expression (Cisternas et al. 2017). Thus, hormonal and genetic factors interact to regulate the expression of the key enzyme necessary for brain masculinization during development. Differences in the local production of estradiol by aromatization of testosterone due to genetic factors could impact on the arrangement of neural circuits underlying male and female behavior.

\section{Transgenic mice hypersecreting hCG: a mouse model for endogenously elevated gonadal steroids}

An increased gonadal response to luteinizing hormone (LH) or hCG leads to enhanced steroidogenesis through the LH/hCG receptor. hCG has a higher receptor affinity and a longer circulating half-life than LH, due to the carbohydrates associated to its molecule (Banerjee \& Fazleabas 2011, Choi \& Smitz 2014). hCG is normally secreted by the human trophoblastic cells 


\section{Males}
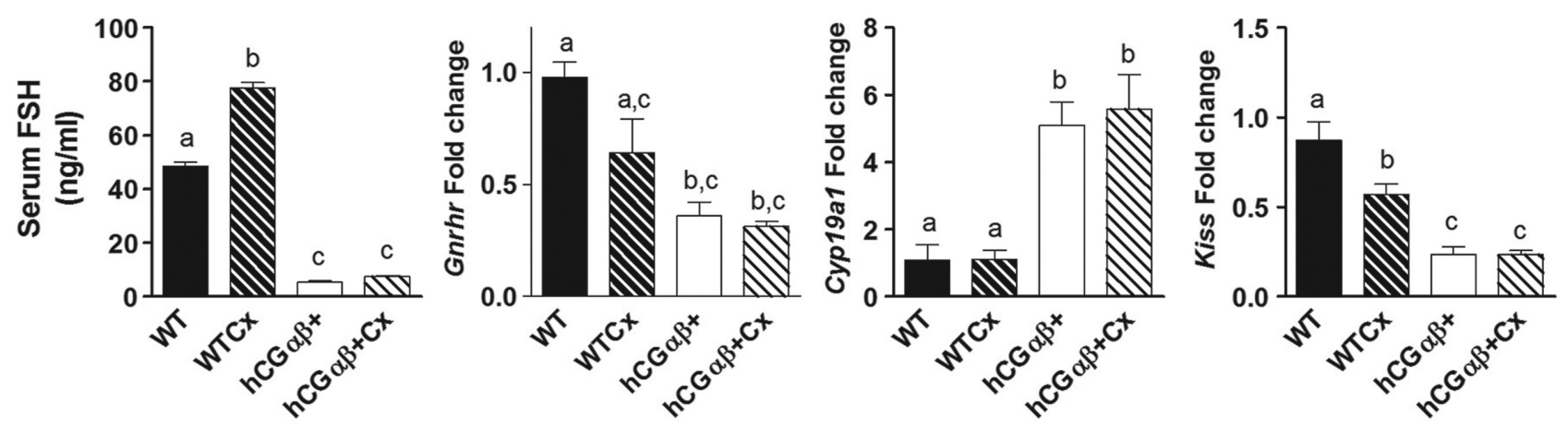

Females
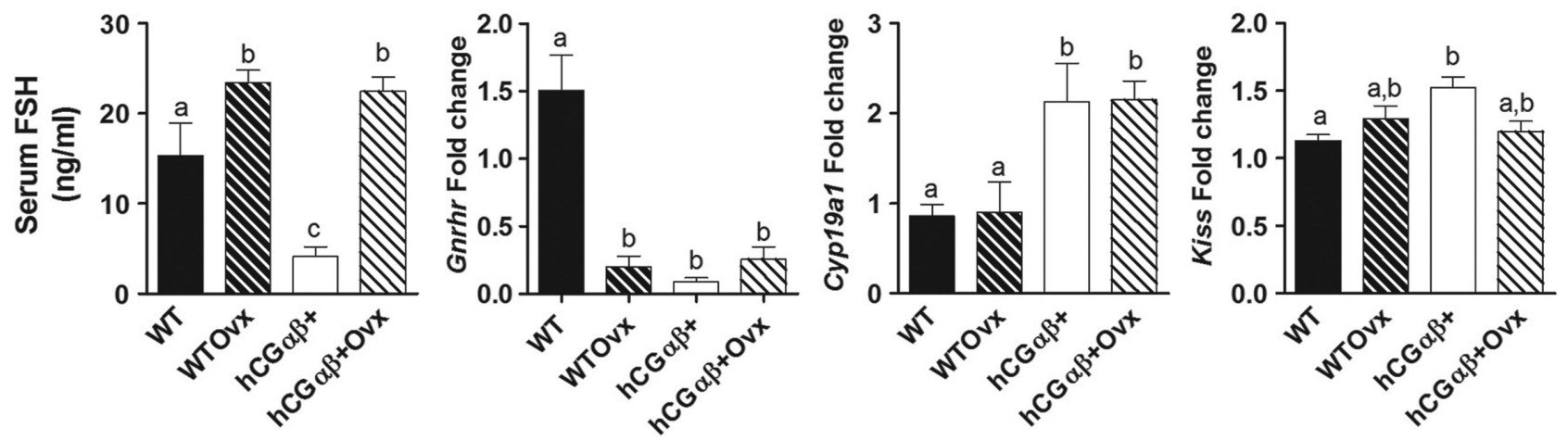

Figure 2 Effect of castration on the hypothalamic-pituitary axis of transgenic male and female mice hypersecreting hCG (hCG $\alpha \beta+)$. Serum FSH levels and gene expression of hypothalamic Cyp19a 1 and Kiss 1, and pituitary Gnrhr of prepubertal WT and hCG $\alpha \beta+$ mice after gonadectomy (Cx for males, Ovx for females) are shown. Intact prepubertal WT and hCG $\alpha \beta+$ males and females were used as controls. The relative mRNA expression was carried out by qRT-PCR $(n=4)$. Data are presented as mean \pm S.E.M. Two-way ANOVA, followed by Bonferroni's post hoc test.

Different letters indicate a value of at least $P<0.05$ (adapted from Gonzalez et al. 2011, 2014).

(Fisheletal.1984), beingessential tomaintain progesterone production by the corpus luteum of pregnancy. Various investigations have demonstrated the presence of $\mathrm{LH} / \mathrm{hCG}$ receptors in numerous fetal and adult organs, as well as tumor tissues (lles et al. 2010). Of note is the presence of these receptors in the brain, adipose tissue, pancreas, uterus and endothelial cells, in addition to the gonads (Lei et al. 1993, Cole \& Butler 2012). However, the physiological relevance of these extra-gonadal $\mathrm{LH} / \mathrm{hCG}$ receptors is not completely understood.

We have generated a transgenic mouse model carrying the common $\alpha$ - and hCG $\beta$ subunit genes (hCG $\alpha \beta+$ mice) under a constitutive promoter that leads to the transgene expression from GD10.5 (Rulli et al. 2002 , 2003). These mice hypersecrete hCG, are infertile and suffer significant alterations on the neuroendocrine regulation of the gonadotropin axis, particularly due to an increased gonadal steroid production (Rulli et al. 2002, 2003, Gonzalez et al. 2011, 2014). Even though males and females exhibit substantial differences in their phenotypes, steroid hormones induce important alterations on the gonadotropin synthesis and secretion in both sexes. The main differences appear to be based on the time window in which each sex is particularly sensitive to hormonal changes during development. Whereas the functional $\mathrm{LH} / \mathrm{hCG}$ receptor is normally expressed from GD17 in the mouse testis (O'Shaughnessy et al. 1998), it occurs at PND5 in the mouse ovary (O'Shaughnessy et al. 1997). Therefore, males and females exhibit differential responses to elevated hCG-induced steroids during development: prenatal/neonatal changes in the male and postnatal in the female.

\section{Males}

As a consequence of elevated hCG, transgenic hCG $\alpha \beta+$ males show high levels of testosterone and progesterone, accompanied by an increased weight of androgendependent organs, such as the prostate and seminal 

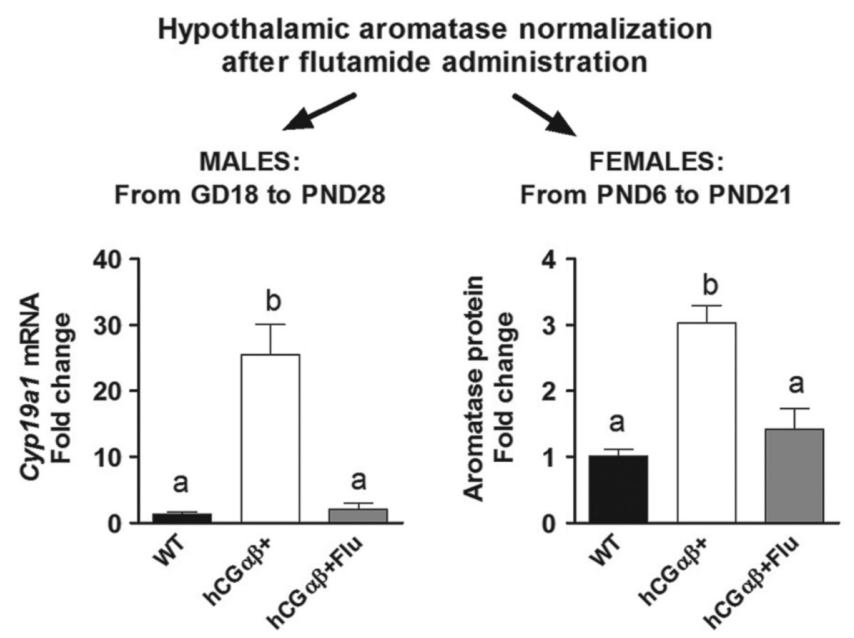

Figure 3 Hypothalamic aromatase after flutamide administration in transgenic mice hypersecreting hCG (hCG $\alpha \beta+)$. In males, flutamide normalized aromatase expression when administered from gestational day 18 (GD18) to postnatal day 28 (PN28); analyzed by qPCR. In females, flutamide normalized aromatase expression when administered from PND6 to PND21; analyzed by western blot. Data are presented as mean \pm S.E.M. Two-way ANOVA, followed by

Bonferroni's post hoc test. Different letters indicate a value of at least $P<0.05$.

vesicles (Rulli et al. 2003, Gonzalez et al. 2011). These males exhibit reduced testicular size and develop Leydig cell adenomas derived from the fetal Leydig cell population (Ahtiainen et al. 2005). The hypothalamicpituitary function of prepubertal hCG $\alpha \beta+$ males is also affected, as manifested by the high hypothalamic GnRH concentration and accelerated GnRH pulse frequency, which induces downregulation of the $\mathrm{GnRH}$ receptor and reduction of $\mathrm{FSH}$ synthesis and secretion at the pituitary level (Gonzalez et al. 2011). Other transgenic models of LH/hCG overexpression (Matzuk et al. 2003) or constitutive activation of LH/hCG receptor (Meehan et al. 2005) also showed low levels of FSH and reduced testicular weight.

Kisspeptin (Kiss 1 ) and its G protein-coupled receptor 54 (Kiss 1r) are essential components of the HPG axis and the onset of puberty, by controlling gonadotropin secretion through $\mathrm{GnRH}$ stimulation. Different studies show that kisspeptin control of GnRH occurs by modulating the negative feedback mechanism of gonadal steroids in both sexes (Clarkson 2013, Poling \& Kauffman 2013). Neonatal administration of estrogenic compounds results in a dose-dependent decrease of Kiss 1 expression in prepubertal males and females (Navarro et al. 2009). Prepubertal hCG $\alpha \beta+$ males exhibit reduced hypothalamic levels of Kiss 1 expression, which is consistent with the suppressive action of high circulating levels of testosterone and locally converted estrogens through an increased hypothalamic P450 aromatase expression (Cyp19a1) (Fig. 2) (Gonzalez et al. 2011). It was demonstrated that estradiol is able to alter the morphology and synapses of glial cells in the arcuate nucleus (Garcia-Segura et al. 2008). Since GnRH neurons express ER $\beta$ and $\mathrm{LH} / \mathrm{hCG}$ receptor, elevated levels of agonists may alter the physiology of these neurons (Chu et al. 2009). Even though a direct effect of hCG in vivo cannot be discarded, studies performed on fetal hypothalamic neurons in vitro showed that Cyp19a1 expression was not directly affected by hCG (Gonzalez et al. 2014).

Interestingly, FSH levels remain low after prepubertal castration in $\mathrm{hCG} \alpha \beta+$ males, thus indicating that the $\mathrm{FSH}$ response to the androgen feedback regulation is severely affected in these mice. The mRNA expressions of pituitary Gnrhr, hypothalamic Cyp19a1 and Kiss 1 also remain unaltered under these conditions (Fig. 2; Gonzalez et al. 2011). Since the testosterone surge by the time of birth is essential for the establishment of the male sexual behavior and reproductive physiology in mice, the next step was to analyze the effect of androgen deprivation perinatally. The administration of the antiandrogen flutamide to pregnant mothers from GD18 and then from birth to 28 days of age to hCG $\alpha \beta+$ males induced a recovery of $\mathrm{FSH}$ synthesis and secretion, accompanied by a normalization of hypothalamic Cyp19a1 (Fig. 3; Gonzalez et al. 2011). These findings identified a critical time window in which androgens, by acting through their receptor, modulate the activation of the hypothalamic-pituitary axis in these mice. During this period, elevated levels of androgens would induce an irreversible impairment of the hypothalamic function, along with the synthesis and secretion of gonadotropins, processes in which kisspeptin and $\mathrm{GnRH}$ receptor regulation play a key role. In normal conditions, GnRH stimulates the gonadotropic response and cell proliferation during early pituitary differentiation. Moreover, a correct connection between the hypothalamus and the pituitary is necessary for the development of a normal number of thyrotropes and gonadotropes during late gestation, as was shown in sheep (Szarek et al. 2008). On the other hand, the absence of fetal GnRH signaling specifically inhibits the differentiation of $\mathrm{FSH}$-producing gonadotropes (Wen et al. 2010).

This evidence shows that the low levels of $\mathrm{FSH}$ associated with the persistently elevated hCG would not be solely due to the negative feedback exerted by gonadal steroids, but to a failure in the perinatal programming exerted by androgens and/or their locally-produced neurosteroids on the developing hypothalamic-pituitary unit of hCG $\alpha \beta+$ males. All these changes ultimately impact on the fertility of these mice at adulthood.

\section{Females}

Numerous studies have been published about the effect of androgens on the female developmental 


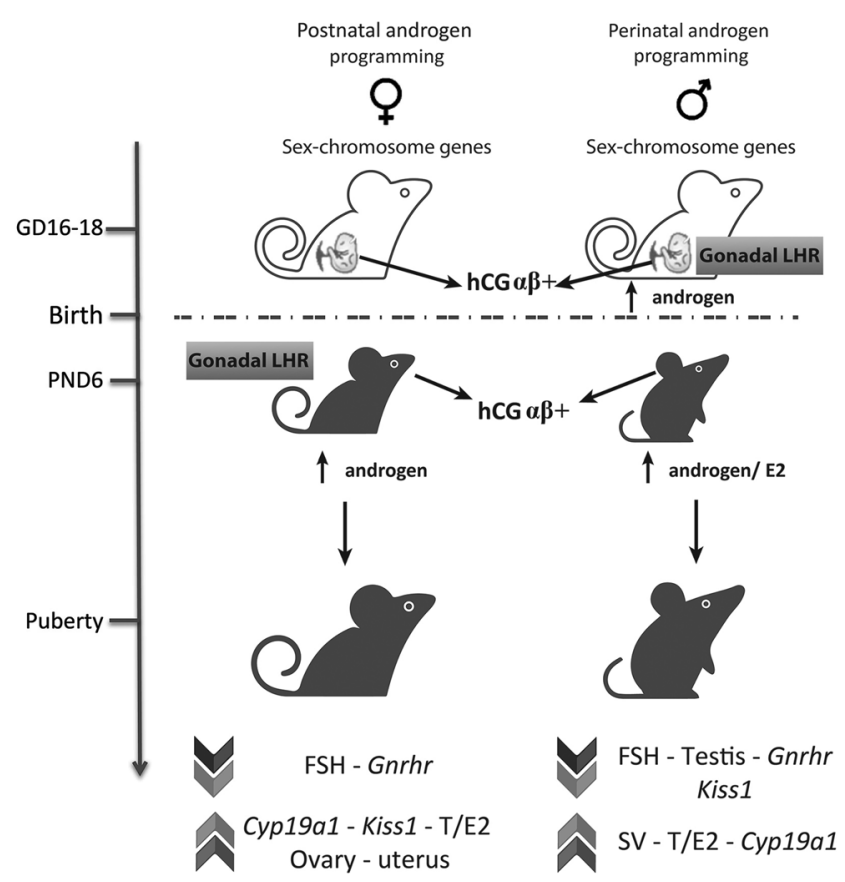

Figure 4 Summary of the impact of persistent hCG stimulation on the developmental programming of the hypothalamic-pituitary axis in both transgenic hCG hypersecreting male and female mice (hCG $\alpha \beta+$; perinatal in males, and postnatal in females). Cyp19a1, P450 aromatase (Gonzalez et al. 2011, 2014); E2, estradiol; FSH, follicle stimulating hormone; GD 16-18, gestational day 16-18; Gnrhr, Gonadotropin releasing hormone receptor; Kiss 1, kisspeptin 1; LHR, luteinizing hormone receptor; PND6, postnatal day 6; SV, seminal vesicles; $\mathrm{T}$, testosterone.

programming, which in turn would impact on the metabolic, behavioral and reproductive function at adulthood. Administration of testosterone propionate to female rats induces several reproductive alterations, depending on the time window of administration, that is, fetal, neonatal or late postnatal age (Tyndall et al. 2012, Paixao et al. 2017). Prenatal administration of testosterone or DHT to mice or rats induces acyclicity, advanced puberty and infertility at adulthood. Additionally, the early postnatal exposure to androgens is also capable of inducing ovulatory dysfunctions and alterations in mating behavior. Thus, early exposure to an excess of androgens during fetal or postnatal life would induce long-lasting alterations on the reproductive programming.

As demonstrated in males (Gonzalez et al. 2011), the regulation of the hypothalamic-pituitary unit is also affected in transgenic hCG $\alpha \beta+$ females (Gonzalez et al. 2014). These females show elevated testosterone levels at least from PND14 onward. These are expected to be high by the second week of life, considering that the $\mathrm{LH}$ receptor is active by PND5 in the mouse ovary (O'Shaughnessy et al. 1997). In normal conditions, a FSH surge occurs during the first two weeks, when the pituitary-gonadal feedback regulation is not fully active (Dullaart et al. 1975). In hCG $\alpha \beta+$ females, this early FSH surge is suppressed, together with a reduced gene expression of Fshb, Lhb and Gnrhr at the pituitary level (Fig. 2; Gonzalez et al. 2014). In addition, precocious puberty is accompanied by a transient surge of estradiol. This evidence suggests that the negative feedback regulation of the gonadotropin axis occurs prematurely in these females. A similar phenotype was found in the bLH $\beta$-CTP mouse model with chronically elevated $\mathrm{LH}$, where high testosterone was present at 14 days of age and led to precocious puberty and transient estradiol elevation (Risma et al. 1997). The expressions of Cyp19a1 and Kiss 1 in the preoptic area, which is the sexually-differentiated hypothalamic area that controls the ovulatory LH surge and displays estradiol-induced positive feedback, are elevated in 21-day-old transgenic females (Fig. 2). In contrast to the phenotype observed in males, hCG $\alpha \beta+$ females are able to respond to ovariectomy at PND14 by increasing serum FSH levels (Fig. 2) and gene expression of pituitary Fshb and Lhb, and also prevents the premature vaginal opening in these mice (Gonzalez et al. 2014). However, as was also demonstrated in $\mathrm{hCG} \alpha \beta+$ males, castration was unable to affect the hypothalamic Kiss 1 and Cyp 19a 1 expression in hCG $\alpha \beta+$ females (Fig. 2). Interestingly, when the antiandrogen flutamide is administered to hCG $\alpha \beta+$ females from PND6 until puberty, aromatase from the preoptic area is normalized (Fig. 3; Gonzalez et al. 2014). These results show that, in females, early exposure to androgens during a critical time- window between the second and third week of life induces sex-specific changes on the hypothalamus that alter the P450 aromatase expression at peripuberty. Consequently, changes in the locally-produced steroids may have implications in the occurrence of abnormal ovulatory LH surge of the reproductive cycles at adulthood, thus culminating in female infertility.

\section{Conclusions}

Differently from experimental models where hyperandrogenism is induced by exogenous administration, transgenic hCG-hypersecreting mice are a useful tool to study how the endogenously produced gonadal steroids in vivo may impact on the male or female reproductive axis (Fig. 4). Nevertheless, the precise mechanisms by which early exposure to steroid hormones affect the reproductive function in males and females are still under debate, even in the light of the new evidence showing the existence of genetic factors that precede gonadal influences during the genesis of differences between the sexes in brain structure (Cisternas et al. 2015, 2017, Arnold 2017). In males, information about the possible influence of elevated androgens on the developmental programming of the hypothalamic-pituitary axis is limited, probably because 
males are normally exposed to androgens from early stages of fetal development and throughout their lives. Evidence derived from transgenic hCG males show that excess of endogenous androgens during a critical time- window between GD18 and PND14 induces long-lasting changes on the reproductive axis, resulting in a premature activation of the hypothalamus and a concomitant silencing of the pituitary gonadotropin production and seems to be the cause of infertility in adulthood. In females, early exposure of steroids during a critical period between PND6 to 14 induces sexspecific organizational changes of the hypothalamus. These changes would have an effect at the preoptic area and alter the P450 aromatase expression, which in turn, would have an impact on the ovulatory cycles and fertility at adulthood. In both sexes, androgens and their locally produced neurosteroids might play a key role in the dysregulation of the hypothalamic-pituitary function during development.

\section{Declaration of interest}

The authors declare that there is no conflict of interest that could be perceived as prejudicing the impartiality of this review.

\section{Funding}

This work was supported by grants from CONICET (PIP 080 and 597); Roemmers Foundation; Fundación René Barón, ANPCYT (PICT 2015- 1333) and SECYT-UNC, Argentina.

\section{References}

Abbott DH, Tarantal AF \& Dumesic DA 2009 Fetal, infant, adolescent and adult phenotypes of polycystic ovary syndrome in prenatally androgenized female Rhesus monkeys. American Journal of Primatology 71 776-784. (https://doi.org/10.1002/ajp.20679)

Ahtiainen P, Rulli S, Pelliniemi LJ, Toppari J, Poutanen M \& Huhtaniemi I 2005 Fetal but not adult Leydig cells are susceptible to adenoma formation in response to persistently high hCG level; a study on hCG overexpressing transgenic mice. Oncogene 24 7301-7309. (https://doi. org/10.1038/sj.onc.1208893)

Arnold AP 2017 A general theory of sexual differentiation. Journal of Neuroscience Research 95 291-300. (https://doi.org/10.1002/ jnr.23884)

Arnold AP \& Chen X 2009 What does the 'four core genotypes' mouse model tell us about sex differences in the brain and other tissues? Frontiers in Neuroendocrinology 30 1-9. (https://doi.org/10.1016/j. yfrne.2008.11.001)

Arnold AP, Chen X, Link JC, Itoh Y \& Reue K 2013 Cell-autonomous sex determination outside of the gonad. Developmental Dynamics 242 371-379. (https://doi.org/10.1002/dvdy.23936)

Bakker J \& Baum MJ 2008 Role for estradiol in female-typical brain and behavioral sexual differentiation. Frontiers in Neuroendocrinology 29 1-16. (https://doi.org/10.1016/j.yfrne.2007.06.001)

Bakker J, De Mees C, Douhard Q, Balthazart J, Gabant P, Szpirer J \& Szpirer C 2006 Alpha-fetoprotein protects the developing female mouse brain from masculinization and defeminization by estrogens. Nature Neuroscience 9 220-226. (https://doi.org/10.1038/nn1624)

Banerjee P \& Fazleabas AT 2011 Extragonadal actions of chorionic gonadotropin. Reviews in Endocrine and Metabolic Disorders 12 323-332. (https://doi.org/10.1007/s11154-011-9193-1)
Carruth LL, Reisert I \& Arnold AP 2002 Sex chromosome genes directly affect brain sexual differentiation. Nature Neuroscience 5 933-934. (https://doi.org/10.1038/nn922)

Chen X, Watkins R, Delot E, Reliene R, Schiestl RH, Burgoyne PS \& Arnold AP 2008 Sex difference in neural tube defects in p53-null mice is caused by differences in the complement of $X$ not $Y$ genes. Developmental Neurobiology 68 265-273. (https://doi.org/10.1002/ dneu.20581)

Choi J \& Smitz J 2014 Luteinizing hormone and human chorionic gonadotropin: distinguishing unique physiologic roles. Gynecological Endocrinology 30 174-181. (https://doi.org/10.3109/09513590.2013.8 59670)

Chu Z, Andrade J, Shupnik MA \& Moenter SM 2009 Differential regulation of gonadotropin-releasing hormone neuron activity and membrane properties by acutely applied estradiol: dependence on dose and estrogen receptor subtype. Journal of Neuroscience 29 5616-5627. (https://doi.org/10.1523/JNEUROSCI.0352-09.2009)

Cisternas CD, Tome K, Caeiro XE, Dadam FM, Garcia-Segura LM \& Cambiasso MJ 2015 Sex chromosome complement determines sex differences in aromatase expression and regulation in the stria terminalis and anterior amygdala of the developing mouse brain. Molecular and Cellular Endocrinology 414 99-110. (https://doi.org/10.1016/j. mce.2015.07.027)

Cisternas CD, Cabrera Zapata LE, Arevalo MA, Garcia-Segura LM \& Cambiasso MJ 2017 Regulation of aromatase expression in the anterior amygdala of the developing mouse brain depends on ER $\beta$ and sex chromosome complement. Scientific Reports 7 5320. (https://doi. org/10.1038/s41598-017-05658-6)

Clarkson J 2013 Effects of estradiol on kisspeptin neurons during puberty. Frontiers in Neuroendocrinology 34 120-131. (https://doi.org/10.1016/j. yfrne.2013.02.002)

Cole LA \& Butler S 2012 Hyperglycosylated hCG, hCG $\beta$ and hyperglycosylated hCG $\beta$ : interchangeable cancer promoters. Molecular and Cellular Endocrinology 349 232-238. (https://doi.org/10.1016/j. mce.2011.10.029)

De Vries GJ, Rissman EF, Simerly RB, Yang LY, Scordalakes EM, Auger CJ, Swain A, Lovell-Badge R, Burgoyne PS \& Arnold AP 2002 A model system for study of sex chromosome effects on sexually dimorphic neural and behavioral traits. Journal of Neuroscience 22 9005-9014. (https://doi.org/10.1523/JNEUROSCI.22-20-09005.2002)

Dullaart J, Kent J \& Ryle M 1975 Serum gonadotrophin concentrations in infantile female mice. Journal of Reproduction and Fertility 43 189-192. (https://doi.org/10.1530/jrf.0.0430189)

Fishel SB, Edwards RG \& Evans CJ 1984 Human chorionic gonadotropin secreted by preimplantation embryos cultured in vitro. Science $\mathbf{2 2 3}$ 816-818. (https://doi.org/10.1126/science.6546453)

Forger NG, Strahan JA \& Castillo-Ruiz A 2015 Cellular and molecular mechanisms of sexual differentiation in the mammalian nervous system. Frontiers in Neuroendocrinology 40 67-86. (https://doi.org/10.1016/j. yfrne.2016.01.001)

Garcia-Segura LM, Lorenz B \& DonCarlos LL 2008 The role of glia in the hypothalamus: implications for gonadal steroid feedback and reproductive neuroendocrine output. Reproduction 135 419-429. (https://doi.org/10.1530/REP-07-0540)

Gluckman PD, Hanson A, Cooper C \& Thornburg KL 2008 Effect of in utero and early-life conditions on adult health and disease. New England Journal of Medicine 359 61-73. (https://doi.org/10.1056/ NEJMra0708473)

Gonzalez B, Ratner LD, Di Giorgio NP, Poutanen M, Huhtaniemi IT, Calandra RS, Lux-Lantos VA \& Rulli SB 2011 Endogenously elevated androgens alter the developmental programming of the hypothalamicpituitary axis in male mice. Molecular and Cellular Endocrinology 332 78-87. (https://doi.org/10.1016/j.mce.2010.09.016)

Gonzalez B, Ratner LD, Scerbo MJ, Di Giorgio NP, Poutanen M, Huhtaniemi IT, Calandra RS, Lux-Lantos VA, Cambiasso MJ \& Rulli SB 2014 Elevated hypothalamic aromatization at the onset of precocious puberty in transgenic female mice hypersecreting human chorionic gonadotropin: effect of androgens. Molecular and Cellular Endocrinology 390 102-111. (https://doi.org/10.1016/j. mce.2014.04.005)

Gore AC, Chappell VA, Fenton SE, Flaws JA, Nadal A, Prins GS, Toppari J \& Zoeller RT 2015 EDC-2: the Endocrine Society's second scientific 
statement on endocrine-disrupting chemicals. Endocrine Reviews 36 E1-E150. (https://doi.org/10.1210/er.2015-1010)

Gorski RA 1985 Sexual differentiation of the brain: possible mechanisms and implications. Canadian Journal of Physiology and Pharmacology 63 577-594. (https://doi.org/10.1139/y85-098)

Hakim C, Padmanabhan V \& Vyas AK 2017 Gestational hyperandrogenism in developmental programming. Endocrinology 158 199-212. (https:// doi.org/10.1210/en.2016-1801)

Halakivi-Clarke L, Cho E, Onojafe I, Liao DJ \& Clarke R 2000 Maternal exposure to tamoxifen during pregnancy increases carcinogen-induced mammary tumorigenesis among female rat offspring. Clinical Cancer Research 6 305-308.

Homburg R 2009 Androgen circle of polycystic ovary syndrome. Human Reproduction 24 1548-1555. (https://doi.org/10.1093/humrep/dep049)

Huhtaniemi I 1994 Fetal testis - a very special endocrine organ. European Journal of Endocrinology 130 25-31. (https://doi.org/10.1530/ eje.0.1300025)

Iles RK, Delves PJ \& Butler SA 2010 Does hCG or hCG $\beta$ play a role in cancer cell biology? Molecular and Cellular Endocrinology 329 62-70. (https://doi.org/10.1016/j.mce.2010.07.014)

Itoh Y, Mackie R, Kampf K, Domadia S, Brown JD, O'Neill R \& Arnold AP 2015 Four core genotypes mouse model: localization of the Sry transgene and bioassay for testicular hormone levels. BMC Research Notes 8 1-7. (https://doi.org/10.1186/1756-0500-8-1)

Konkle AT \& McCarthy MM 2011 Developmental time course of estradiol, testosterone, and dihydrotestosterone levels in discrete regions of male and female rat brain. Endocrinology 152 223-235. (https://doi. org/10.1210/en.2010-0607)

Kuiper GG, Shughrue PJ, Merchenthaler I \& Gustafsson JA 1998 The estrogen receptor beta subtype: a novel mediator of estrogen action in neuroendocrine systems. Frontiers in Neuroendocrinology 19 253-286. (https://doi.org/10.1006/frne.1998.0170)

Lei ZM, Rao CV, Kornyei JL, Licht P \& Hiatt ES 1993 Novel expression of human chorionic gonadotropin/luteinizing hormone receptor gene in brain. Endocrinology 132 2262-2270. (https://doi.org/10.1210/ endo.132.5.8477671)

Matzuk MM, De Mayo FJ, Hadsell LA \& Kumar TR 2003 Overexpression of human chorionic gonadotropin causes multiple reproductive defects in transgenic mice. Biology of Reproduction 69 338-346. (https://doi. org/10.1095/biolreprod.102.013953)

McCarthy MM 2008 Estradiol and the developing brain. Physiological Reviews 88 91-134. (https://doi.org/10.1152/physrev.00010.2007)

Meehan TP, Harmon BG, Overcast ME, Yu KK, Camper SA, Puett D \& Narayan P 2005 Gonadal defects and hormonal alterations in transgenic mice expressing a single chain human chorionic gonadotropin-lutropin receptor complex. Journal of Molecular Endocrinology 34 489-503. (https://doi.org/10.1677/jme.1.01669)

Navarro VM, Sánchez-Garrido MA, Castellano JM, Roa J, GarcíaGaliano D, Pineda R, Aguilar E, Pinilla L \& Tena-Sempere M 2009 Persistent impairment of hypothalamic KiSS-1 system after exposures to estrogenic compounds at critical periods of brain sex differentiation. Endocrinology 150 2359-2367. (https://doi.org/10.1210/en.20080580)

Negri-Cesi P, Colciago A, Pravettoni A, Casati L, Conti L \& Celotti F 2008 Sexual differentiation of the rodent hypothalamus: hormonal and environmental influences. Journal of Steroid Biochemistry and Molecular Biology 109 294-299. (https://doi.org/10.1016/j. jsbmb.2008.03.003)

Nugent BM, Wright CL, Shetty AC, Hodes GE, Lenz KM, Mahurkar A, Russo SJ, Devine SE \& McCarthy MM 2015 Brain feminization requires active repression of masculinization via DNA methylation. Nature Neuroscience 18 690-697. (https://doi.org/10.1038/nn.3988)

O'Shaughnessy PJ, McLelland D \& McBride MW 1997 Regulation of luteinizing hormone-receptor and follicle-stimulating hormone-receptor messenger ribonucleic acid levels during development in the neonatal mouse ovary. Biology of Reproduction 57 602-608.

O'Shaughnessy PJ, Baker P, Sohnius U, Haavisto AM, Charlton HM \& Huhtaniemi I 1998 Fetal development of Leydig cell activity in the mouse is independent of pituitary gonadotroph function. Endocrinology $1391141-1146$
Padmanabhan V \& Veiga-Lopez A 2013 Sheep models of polycystic ovary syndrome phenotype. Molecular and Cellular Endocrinology 373 8-20. (https://doi.org/10.1016/j.mce.2012.10.005)

Paixao L, Ramos RB, Lavarda A, Morsh DM \& Spritzer PM 2017 Animal models of hyperandrogenism and ovarian morphology changes as features of polycystic ovary syndrome: a systematic review. Reproductive Biology and Endocrinology 15 12. (https://doi.org/10.1186/s12958-0170231-z)

Palaszynski KM, Smith DL, Kamrava S, Burgoyne PS, Arnold AP \& Voskuhl RR 2005 A Yin-Yang effect between sex chromosome complement and sex hormones on the immune response. Endocrinology 146 3280-3285. (https://doi.org/10.1210/en.2005-0284)

Palmer JR, Wise LA, Hatch EE, Troisi R, Titus-Ernstoff L, Strohsnitter W, Kaufman R, Herbst AL, Noller KL, Hyer M et al. 2006 Prenatal diethylstilbestrol exposure and risk of breast cancer. Cancer Epidemiology, Biomarkers and Prevention 15 1509-1514. (https://doi. org/10.1158/1055-9965.EPI-06-0109)

Poling MC \& Kauffman AS 2013 Organizational and activational effects of sex steroids on kisspeptin neuron development. Frontiers in Neuroendocrinology 34 3-17. (https://doi.org/10.1016/j.yfrne.2012.06.001)

Rhees RW, Kirk BA, Sephton S \& Lephart ED 1997 Effects of prenatal testosterone on sexual behavior, reproductive morphology and $\mathrm{LH}$ secretion in the female rat. Developmental Neuroscience 19 430-437. (https://doi.org/10.1159/000111240)

Rhoda J, Corbier P \& Roffi J 1984 Gonadal steroid concentrations in serum and hypothalamus of the rat at birth: aromatization of testosterone to 17 alpha-estradiol. Endocrinology 114 1754-1760. (https://doi. org/10.1210/endo-114-5-1754)

Risma KA, Hirshfield AN \& Nilson JH 1997 Elevated luteinizing hormone in prepubertal transgenic mice causes hyperandrogenemia, precocious puberty, and substantial ovarian pathology. Endocrinology 138 3540-3547. (https://doi.org/10.1210/endo.138.8.5313)

Robinson J 2006 Prenatal programming of the female reproductive neuroendocrine system by androgens. Reproduction 132 539-547. (https://doi.org/10.1530/rep.1.00064)

Ruiz-Palmero I, Hernando M, Garcia-Segura LM \& Arevalo MA 2013 $\mathrm{G}$ protein-coupled estrogen receptor is required for the neuritogenic mechanism of $17 \beta$-estradiol in developing hippocampal neurons. Molecular and Cellular Endocrinology 372 105-115. (https://doi. org/10.1016/j.mce.2013.03.018)

Rulli SB, Kuorelahti A, Karaer O, Pelliniemi LJ, Poutanen M \& Huhtaniemi I 2002 Reproductive disturbances, pituitary lactotrope adenomas, and mammary gland tumors in transgenic female mice producing high levels of human chorionic gonadotropin. Endocrinology 143 4084-4095. (https://doi.org/10.1210/en.2002-220490)

Rulli SB, Ahtiainen P, Mäkelä S, Toppari J, Poutanen M \& Huhtaniemi I 2003 Elevated steroidogenesis, defective reproductive organs, and infertility in transgenic male mice overexpressing human chorionic gonadotropin. Endocrinology 144 4980-4990. (https://doi.org/10.1210/ en.2003-0403)

Scerbo MJ, Freire-Regatillo A, Cisternas CD, Brunotto M, Arevalo MA, Garcia-Segura LM \& Cambiasso MJ 2014 Neurogenin 3 mediates sex chromosome effects on the generation of sex differences in hypothalamic neuronal development. Frontiers in Cellular Neuroscience $81 \mathrm{e} 13$.

Seney ML, Chang LC, Oh H, Wang X, Tseng GC, Lewis DA \& Sibille E $2013 a$ The role of genetic sex in affect regulation and expression of GABA-related genes across species. Frontiers in Psychiatry 4104.

Seney ML, Ekong KI, Ding Y, Tseng GC \& Sibille E 2013b Sex chromosome complement regulates expression of mood-related genes. Biology of Sex Differences 4 20. (https://doi.org/10.1186/2042-6410-4-20)

Smith-Bouvier DL, Divekar AA, Sasidhar M, Du S, Tiwari-Woodruff SK, King JK, Arnold AP, Singh RR \& Voskuhl RR 2008 A role for sex chromosome complement in the female bias in autoimmune disease. Journal of Experimental Medicine 205 1099-1108. (https://doi. org/10.1084/jem.20070850)

Szarek E, Farrand K, McMillen IC, Young IR, Houghton D \& Schwartz J 2008 Hypothalamic input is required for development of normal numbers of thyrotropes and gonadotropes, but not other anterior pituitary cells in late gestation sheep. Journal of Physiology 586 1185-1194. (https://doi. org/10.1113/jphysiol.2007.141523) 
Tyndall V, Broyde M, Sharpe R, Welsh M, Drake AJ \& McNeilly AS 2012 Effect of androgen treatment during foetal and/or neonatal life on ovarian function in prepubertal and adult rats. Reproduction 143 21-33. (https:// doi.org/10.1530/REP-11-0239)

Weisz J \& Ward IL 1980 Plasma testosterone and progesterone titers of pregnant rats, their male and female fetuses, and neonatal offspring. Endocrinology 106 306-316. (https://doi.org/10.1210/endo-106-1-306)

Wen S, Ai W, Alim Z \& Boehm U 2010 Embryonic gonadotropinreleasing hormone signaling is necessary for maturation of the male reproductive axis. PNAS 107 16372-16377. (https://doi.org/10.1073/ pnas.1000423107)
Wilson CA \& Davies DC 2007 The control of sexual differentiation of the reproductive system and brain. Reproduction 133 331-359. (https://doi. org/10.1530/REP-06-0078)

Received 31 January 2018

First decision 12 March 2018

Revised manuscript received 6 June 2018

Accepted 25 June 2018 